\title{
Measurement of Height of Mt. Sagarmatha
}

\author{
Susheel Dangol, Prakash Joshi, Suraj KC, Mahesh Thapa, \\ Bigyan Banjara, Shanker KC, Stallin Bhandari \\ susheel.dangol@nepal.gov.np, lightjoshiji@gmail.com, kcsuraj21@gmail.com, mahesh100thapa@ \\ gmail.com, bigyan.banjara@nepal.gov.np, \\ shankerkc01@gmail.com, stallin.bhandari@gmail.com
}

\section{KEYWORDS}

Sagarmatha, Orthometric Height, Joint Announcement

\begin{abstract}
The height measurement of the highest peak of the world "Sagarmatha" was conducted by Nepal for the first time. The methodology for the measurement was finalized from the workshop held in Kathmandu with the constructive comments from national and international experts. Trignometrical levelling, precise levelling, GNSS survey and gravity survey was conducted. Previous air borne gravity data and present surface gravity data was used to determine the precise regional geoid for this program. Thus orthometric height was determined as $8848.86 \mathrm{~m}$ from the ellipsoid height observed at the top of Sagarmatha and precise geoid determined. The height was determined on the base of International Height Reference System (IHRS) and final height was announced jointly from Nepal and China on 8th of December 2020 from Kathmandu and Beijing through virtual media.
\end{abstract}

\section{BACKGROUND}

Mt. Sagarmatha, the highest peak of the world which was discovered by geodetic survey (Angus-Leppan, 1982), has always been a national pride of Nepal. Since the identification of the peak as the highest peak of the world, several measurements of its height have been conducted in the past. It was first observed by J W Armstrong of Survey of India and named 'Peak b' which was later named 'Peak h' and then 'Peak XV' (Ward, 1995). J. W. Armstrong determined the height of Sagarmatha in 1847 as $8779 \mathrm{~m}$ (28799 $\mathrm{ft}$ ) (Gulatee, 1954). In 1905, Burrard calculated the height of Sagarmatha as $8882 \mathrm{~m}$ (29141 ft) (Gulatee, 1954). Andrew Waugh and Nicholson determined its height as $8840 \mathrm{~m}$ (29002 ft) in 1849 (Gulatee, 1954). In 1954 , B. L. Gulatee precisely calculated the height of Sagarmatha as $8848 \mathrm{~m}(290028 \mathrm{ft})$ (Gulatee, 1954). In 1975, Chinese geodetic surveyors measured the height of Sagarmatha and determined its height as $8848.13 \mathrm{~m}$ (Dansheng, 1979). Italian surveyors in 1992 determined the snow height of the Sagarmatha as $8848.65 \mathrm{~m}$ (Beinat et. al. 1992). In 1999, Washburn and Chen determined the height of Sagarmatha as $8850 \mathrm{~m}$ (Poretti, et. al, 2006). In 2004, Italian surveyor determined the rock height of Sagarmatha as $8848.82 \mathrm{~m}$ and snow height as $8852.12 \mathrm{~m}$ (Poretti, et. al., 2006). In 2005, State Bureau of Surveying and Mapping (SBSM) of china determined the rock height of Sagarmatha as $8844.43 \mathrm{~m}$ (Yamin, 2007). The orthometric heights of the snow surface and rock surface of the summit were determined as $8847.93 \mathrm{~m}$ and $8844.43 \mathrm{~m}$ respectively 
in the 2005 height measurement by China (Chen, et.al, 2010, Chen, et. al., 2006). Table 1 shows some history of height determination of Sagarmatha.

Table 1 : History of Sagarmatha height measurement.

\begin{tabular}{|c|l|c|}
\hline S.N. & \multicolumn{1}{|c|}{ Measurement by } & $\begin{array}{c}\text { Geoidal } \\
\text { elevation }\end{array}$ \\
\hline 1 & Survey of India, 1849 & 8840 \\
\hline 2 & Sidney Burrard, 1905 & 8882 \\
\hline 3 & De Graaf Hunter, 1930 & 8854 \\
\hline 4 & B. L. Gulatee, 1954 & 8848 \\
\hline 5 & Desio and Caporali, 1987 & 8872 \\
\hline 6 & Ev-K2-CNR/SBSM, 1992 & 8848.65 \\
\hline 7 & J.Y. Chen, 1999 & 8849.71 \\
\hline 8 & Washburn \& Chen, 1999 & 8850 \\
\hline 9 & EGM 96 & 8849.82 \\
\hline
\end{tabular}

Source: Poretti, et. al., 2006

In spite of different height of Sagarmatha determined by different organizations, Nepal and the world have been adopting the height determined by B. L. Gulatee in 1954. In the mean time, devastating earthquakes triggered Nepal and arouse the question on change in the height of Sagarmatha due to the earthquake. Hence, to answer this probable query, Survey Department, Government of Nepal conducted the program to measure the height of Sagarmatha.

\section{OBJECTIVE}

The major objective of this research is to determine the updated orthometric height of the Sagarmatha after devastating earthquake of 2015. Secondary objectives of the research are as follows:

- Establishment of Permannent Bench Marks in the major road alignment of Siraha, Udaypur, Okhaldhunga and Solokumbu district which will be useful in the different engineering and construction works in future

- Establishment and strengthening of GNSS control points in the Siraha,
Udaypur, Okhaldhunga, Khotang, Bhojpur, Ramechhap, Dolakha and other surrounding districts

- Derivation of highly accurate Geoid for the Sagarmatha region

\section{STUDY AREA}

For this program, the study area was selected as such, the regional Geoid can be computed.

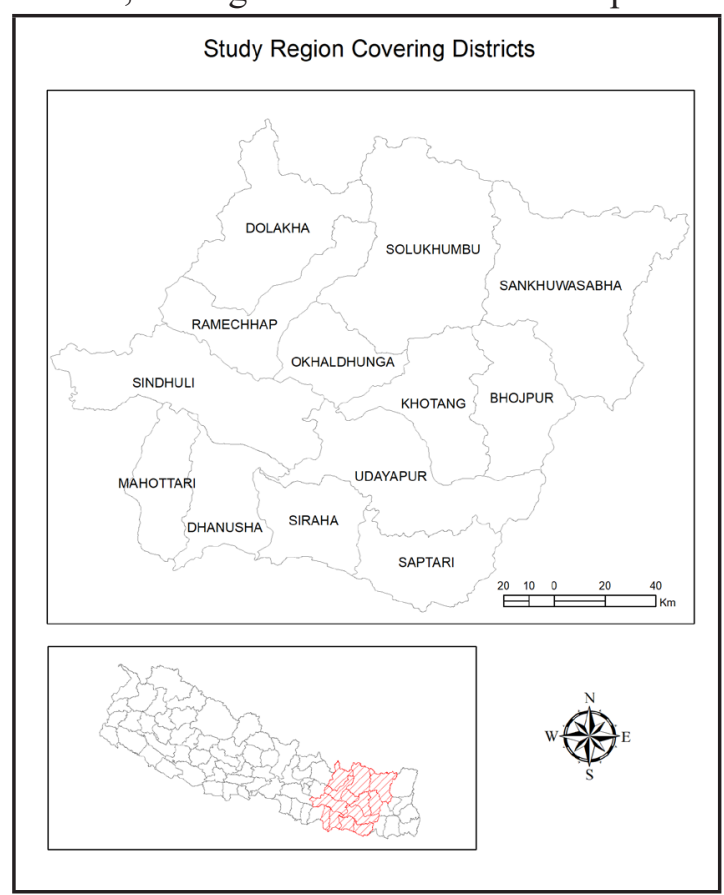

Figure 1: District covered for the study.

For this reason, thirteen districts at the periphery of the Sagarmatha were selected which include Sankhuwasabha, Solukhumbu, Dolakha, Ramechhap, Okhaldhunga, Khotang, Bhojpur, Udaypur, Sindhuli, Mahottari, Dhanusha, Siraha and Saptari. The area was chosen such that the Sagarmatha lies at almost middle from east to west. The survey works were evenly distributed over the study area which covers thirteen districts (Figure 1).

\section{METHODOLOGY}

Different methods were followed in the past during measurement of the height of Sagarmatha. However, it can be seen that the latest available technology had been used during that observation and the technology 
adopted were seen gradually advanced according to the time of observation.

\subsection{History of Sagarmatha Measurement}

Differentmethodswereadoptedduring previous Sagarmatha measurement. J. W. Armstrong used distance and vertical angle to determine the height of Sagarmatha in 1847 (Gulatee, 1954). Waugh conducted trignometrical leveling with reciprocal observations and also consideration of curvature of path and refraction coefficient for calculation of height (Gulatee, 1954). B. L. Gulatee too conducted triangulation and trignometrical leveling for which vertical angles were measured from eight stations viz. Mayam, Laori Danda, Aisyalukharka, Chhulyamu, Pike, Sollung, Upper Rauje and Lower Rauje and deflection of vertical observation was carried out to delineate geoid at Sagarmatha area (Gulatee, 1954). In 1966-68 and 1975 Chinese geodesists carried out two geodetic campaigns which include triangulation, traverse, astronomical and gravimetric measurements for the determination of the height and location of the Sagarmatha (Chen, 1993). The Chinese surveyor team erected a metallic beacon at the top and at the same time, other teams conducted leveling, triangulation, astronomical and gravimetric measurements were conducted (Dansheng, 1979). The height during this survey was determined by a trigonometrical survey from nine points in tibet among which one point was connected to Chinese geodetic height network (Beinat et. al, 1992). The Italian surveyors did triangulation as well as GPS measurement at the top together (Beinat, et. al. 1992). GPS and Ground Penetrating Radar (GPR) survey were conducted to determine the snow height and rock height respectively in 2004 survey by Italians (Poretti, et. al., 2006). In 2005, SBSM conducted GPS measurement at the top of the peak (Yamin, et. al., 2007).

\subsection{Methodology adopted by Nepal}

Draft methodology was prepared at first from the technical team of the Survey Department. This draft methodology was presented to the community of international scientist in the workshop forum organized by Survey Department on 11-12 December 2017. The participants of the workshop were the experts in the field of geodesy and mountain measurements from China, India, Italy, Japan, Nepal, New Zealand, Switzerland and USA. Experts from different countries made presentations on geodesy, GNSS observations and mountain height measurements which include field measurements as well as remote sensing techniques for height measurement. The final methodology was prepared including the comments from the experts. Figure 2 shows the methods adopted by Survey Department for the measurement of the height of Sagarmatha.

For the program, the whole study area was divided into regular grid stretching 50 kilometers left and 50 kilometer right from Mt. Sagarmatha and from northern border to southern border. In the plain area, 10 X $10 \mathrm{~km}$ grid was made and in the remaining area 25 X 25 kilometer grid was made. In each grid, at least one control station was established for GNSS and Gravity survey was conducted. Detail methodology is discussed in the section below.

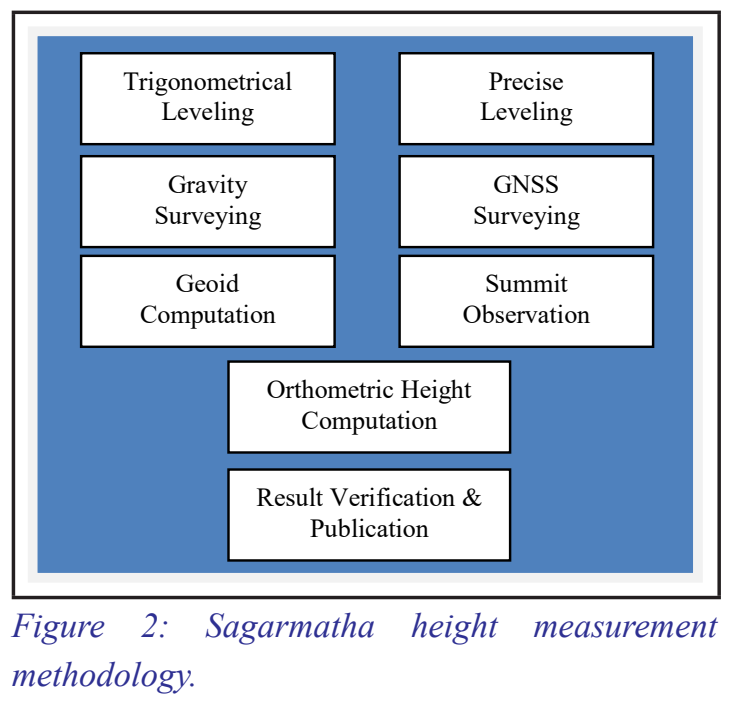




\subsubsection{Trignometrical Leveling}

Triangulation was done at 14 control stations within the study area. Among these stations peak observation was made from 10 stations. Meteorological data were also collected at every station. Figurel 3 shows the control stations from where trignometrical leveling and triangulation survey was conducted.

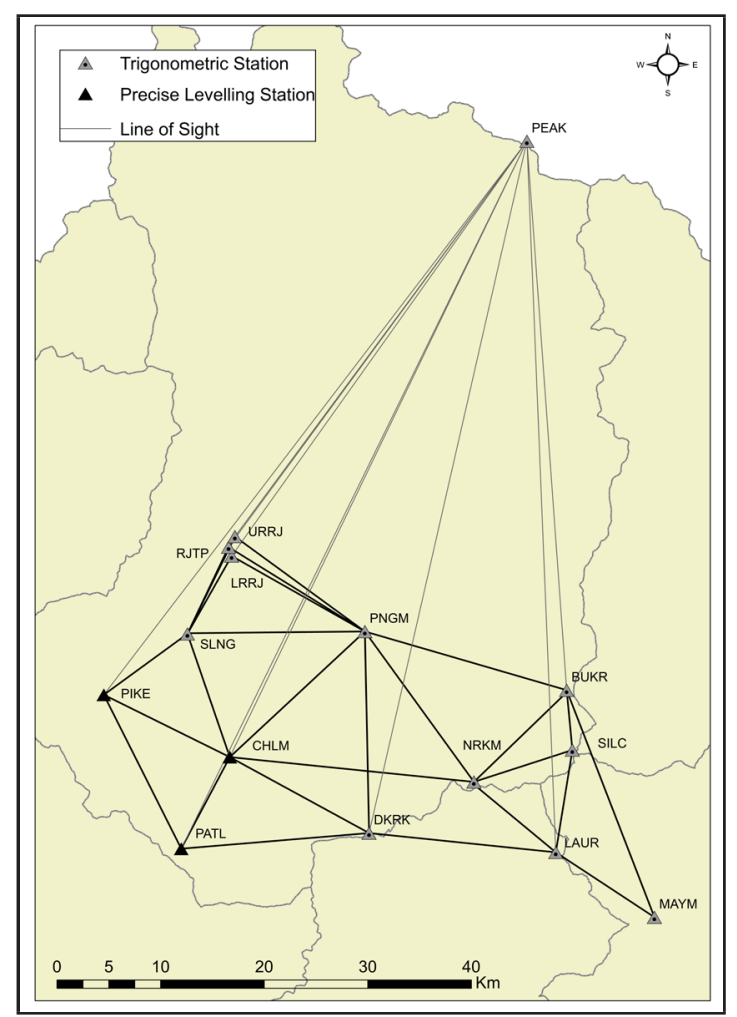

Figure 3: Trignometrical leveling control stations.

\subsubsection{Precise Leveling}

Precise leveling from Maadar of Siraha district of Nepal at the border between Nepal and India to three stations viz. Chhulyamu, Pike and Pattale was conducted. The total length of precise leveling was 248 kilometers. The datum station was established at the Maadar. To this station, height was carried from bench mark from India, which was supported by Survey of India.

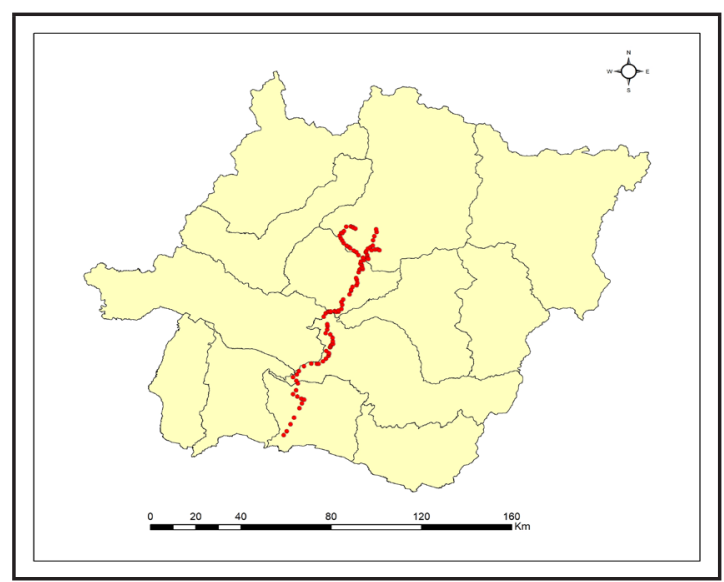

Figure 4: Precise leveling route.

\subsubsection{GNSS Surveying}

GNSS survey was conducted within the districts of study area. For this purpose, whole study area was divided into specific grid. Considering Sagarmatha at the center, the grid was planned to 50 kilometers east and 50 kilometers west from northern border to southern border. $10 \mathrm{~km} \mathrm{X} 10 \mathrm{~km}$ grid was formed at hilly region and $25 \mathrm{~km}$ X $25 \mathrm{~km}$ grid was formed at plain area. The survey was conducted in the control stations established within these grids. Besides these stations, GNSS survey was further conducted at every Permanent Bench Marks (PBM) and Special Bench Mark along the leveling route. GNSS survey was also conducted at the top of Sagarmatha. During GNSS observation at the top, other nine stations were also occupied with the GNSS receiver conducting the survey.

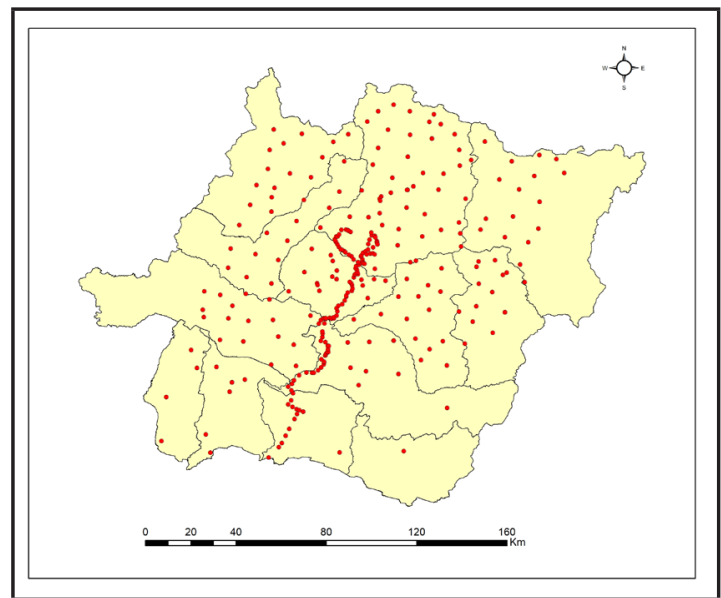

Figure 5: GNSS survey stations. 


\subsubsection{Gravity Surveying}

Gravity survey was conducted at all the stations where GNSS survey was conducted. These observations were used to define the precise geoid. Besides this surface gravity, airborne gravity was also used in order to prepare the geoid of this region.

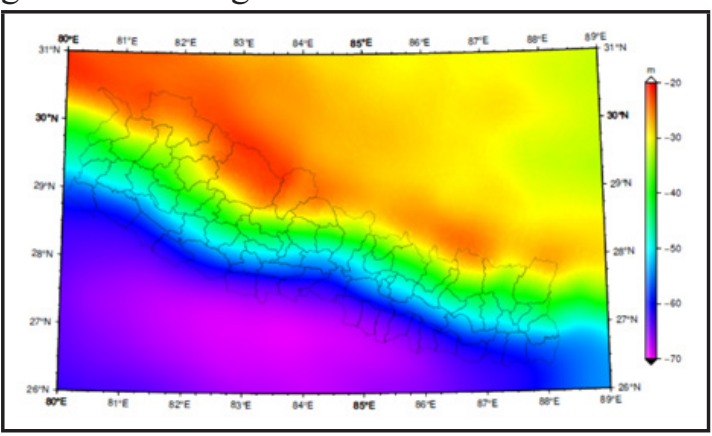

Figure 6: Geoid of Nepal (2020).

\subsection{Field Team Composition}

For the field observation, different teams were mobilized according to the field activity. The field work was started from early 2018 and completed by 2019. All the technical teams were from the Survey Department. Separate teams were mobilized for separate field work like precise leveling, GNSS survey, gravity survey, trignometrical leveling and summit observation. Following table shows the list of technical staff and the team leader for different field work and season.

Table 2 : Precise leveling field team, season 2074/75

\begin{tabular}{|l|l|l|l|}
\hline S.N. & \multicolumn{1}{|c|}{ Name } & S.N. & \multicolumn{1}{|c|}{ Name } \\
\hline 1 & \multicolumn{2}{|l|}{ Rishiram Shrestha (Team Leader) } \\
\hline 2 & Hari Shrestha & 3 & Deepak Ratna Shakya \\
\hline 4 & Rajman Shrestha & 5 & Basanta Shrestha \\
\hline 6 & Purna Bahadur Danekhu & 7 & Ram Prasad Thusa \\
\hline 8 & Gopal Khatri & 9 & Yagya Prasad Adhikari \\
\hline 10 & Janak Raj Joshi & 11 & Shiva Shankar Chaulagai \\
\hline 12 & Bishnu Raj Joshi & 13 & Sumeet Katila \\
\hline 14 & Top Bahadur BK & 15 & Bishal Gautam \\
\hline 16 & Laxman KC & 17 & Grihendra Lamichhane \\
\hline
\end{tabular}

Table 3 : Precise leveling monumentation, season 2075/76.

\begin{tabular}{|c|c|c|c|}
\hline S.N. & Name & S.N. & Name \\
\hline 1 & \multicolumn{3}{|c|}{ Rishiram Shrestha (Team Leader) } \\
\hline 2 & Hari Shrestha & 3 & Deepak Ratna Shakya \\
\hline 4 & Rajman Shrestha & 5 & Basanta Shrestha \\
\hline 6 & Ram Prasad Thusa & 7 & Yagya Prasad Adhikari \\
\hline 8 & Hira Maharjan & 9 & Gopal Khatri \\
\hline 10 & Janak Raj Joshi & 11 & Krishna Dev Raut \\
\hline 12 & Sumeet Katila & 13 & Top Bahadur BK \\
\hline 14 & Shiva Shankar Chaulagai & 15 & Bharat Panthee \\
\hline 16 & Laxman KC & 17 & Bishal Gautam \\
\hline
\end{tabular}

Table 4: Precise leveling field team, season 2075/76

\begin{tabular}{|c|c|c|c|}
\hline S.N. & Name & S.N. & Name \\
\hline 1 & \multicolumn{3}{|c|}{ Rishiram Shrestha (Team Leader) } \\
\hline 2 & Hari Shrestha & 3 & Deepak Ratna Shakya \\
\hline 4 & Rajman Shrestha & 5 & Jeetram Khayergoli \\
\hline 6 & Basanta Shrestha & 7 & Ram Prasad Thusa \\
\hline 8 & Hira Maharjan & 9 & Gopal Khatri \\
\hline 10 & Jeevan Gopali & 11 & Janak Raj Joshi \\
\hline 12 & Narayan Prasad Subedi & 13 & Sumeet Katila \\
\hline 14 & Top Bahadur BK & 15 & Dil Bahadur Tamang \\
\hline 16 & Laxman KC & 17 & Narendra Shrestha \\
\hline
\end{tabular}

Table 5 : Trignometrical leveling monumentation, season 2075/76.

\begin{tabular}{|c|c|c|c|}
\hline S.N. & Name & S.N. & Name \\
\hline 1 & \multicolumn{3}{|c|}{ Nirmal Acharya (Team Leader) } \\
\hline 2 & Purna Ratna Bajracharya & 3 & Suraj Bahadur KC \\
\hline 4 & Sanjeeb Kumar Raut & 5 & Stalin Bhandari \\
\hline 6 & Shanker KC & 7 & Bechan Yadav \\
\hline 8 & Gopal Krishna Kharbuja & 9 & Narayan Prasad Subedi \\
\hline 10 & Shiva Shanker Chaulagai & 11 & Bijay Kumar Manandhar \\
\hline 12 & Basudev Oli & & \\
\hline
\end{tabular}

Table 6 : Trignometrical leveling, season 2076/77.

\begin{tabular}{|l|l|l|l|l|}
\hline S.N. & \multicolumn{1}{|c|}{ Name } & S.N. & \multicolumn{1}{c|}{ Name } \\
\hline 1 & \multicolumn{2}{|l|}{ Rishi Ram Shrestha (Team Leader) } \\
\hline 2 & Purna Ratna Bajracharya & 3 & Gopal Krishna Kharbuja \\
\hline 4 & Shanker KC & 5 & Stalin Bhandari \\
\hline 6 & Narayan Prasad Subedi & 7 & Nagendra Katuwal \\
\hline 8 & Shiva Shanker Chaulagai & 9 & Pravash Kumar Yadav \\
\hline 10 & Bhim Bahadur BK & 11 & Bijay Kumar Manandhar \\
\hline 12 & Govinda Gaudel & 13 & Mahesh Pudashaini \\
\hline
\end{tabular}


Table 7 : GNSS survey, season 2074/75

\begin{tabular}{|l|l|l|l|l|}
\hline S.N. & \multicolumn{1}{|c|}{ Name } & S.N. & \multicolumn{1}{c|}{ Name } \\
\hline 1 & \multicolumn{2}{|l|}{ Ajeet Kunwar (Team Leader) } & \\
\hline 2 & Purna Ratna Bajracharya & 3 & Nawaraj Acharya \\
\hline 4 & Bigyan Banjara & 5 & Mahesh Thapa \\
\hline 6 & Surya Lal Bhomi & 7 & Dipesh Suwal \\
\hline 8 & Binod Humagai & 9 & Umang Raj Dotel \\
\hline 10 & Gopal Krishna Kharbuja & 11 & Hira Bahadur Maharjan \\
\hline 12 & Jeevan Thapa & 13 & Lava Bikram Shrestha \\
\hline 14 & Purushottam Saud & 15 & Amit Kumar Shrestha \\
\hline
\end{tabular}

Table 8 : GNSS Survey, season 2075/76.

\begin{tabular}{|l|l|l|l|}
\hline S.N. & \multicolumn{1}{|c|}{ Name } & S.N. & \multicolumn{1}{l|}{ Name } \\
\hline 1 & \multicolumn{4}{|l|}{ Ajeet Kunwar (Team Leader) } \\
\hline 2 & Bigyan Banjara & 3 & Umang Raj Dotel \\
\hline 4 & Nawaraj Acharya & 5 & Mahesh Thapa \\
\hline 6 & Gopal Krishna Kharbuja & 7 & Shanker KC \\
\hline 8 & Sundar Devkota & 9 & Rabin Prajapati \\
\hline 10 & Mahesh Pudashaini & 11 & Pravash Kumar Yadav \\
\hline 12 & Jeevan Thapa & & \\
\hline
\end{tabular}

Table 9 : GNSS \& Gravity survey at high himalaya, season 2075/76.

\begin{tabular}{|c|c|c|c|}
\hline S.N. & Name & S.N. & Name \\
\hline 1 & \multicolumn{3}{|c|}{ Mahesh Thapa (Team Leader) } \\
\hline 2 & Bigyan Banjara & 3 & Jeevan Thapa \\
\hline 4 & Pravash Kumar Yadav & 5 & Bharat Panthee \\
\hline 6 & Amit Kumar Shrestha & 7 & \\
\hline
\end{tabular}

Table 10: Gravity survey, season 2075/76.

\begin{tabular}{|l|l|}
\hline S.N. & Name \\
\hline 1 & Umang Raj Dotel (Team Leader) \\
\hline 2 & Bharat Panthee \\
\hline
\end{tabular}

Table 11: Gravity survey, season 2076.77 .

\begin{tabular}{|l|l|l|l|}
\hline S.N. & \multicolumn{3}{|c|}{ Name } \\
\hline 1 & Bikash Kumar Singh (Team Leader) \\
\hline 2 & Bharat Panthee & 3 & Jeevan Thapa \\
\hline
\end{tabular}

Table 12: CORS establishment at Lobuche

\begin{tabular}{|c|l|}
\hline S.N. & \multicolumn{1}{|c|}{ Name } \\
\hline & Bigyan Banjara (Team Leader) \\
\hline & Mahesh Thapa \\
\hline
\end{tabular}

Table 13: GNSS survey at the peak.

\begin{tabular}{|l|l|}
\hline S.N. & \multicolumn{1}{|c|}{ Name } \\
\hline 1 & Khimlal Gautam (Team Leader) \\
\hline 2 & Rabin Karki \\
\hline 3 & Suraj Singh Bhandari (Base camp) \\
\hline 4 & Yubaraj Dhital (Base Camp) \\
\hline
\end{tabular}

\section{DATA PROCESSING}

Dedicated team for precise data processing was formed for whole process. The processing team include $\mathrm{Mr}$ Suraj Bahadur $\mathrm{KC}, \mathrm{Mr}$ Mahesh Thapa, Mr Bigyan Banjara, Mr. Shanker KC and Mr Stalin Bhandari. Python was used for processing of trignometrical leveling, Trimble Business Center (TBC) was used for processing precise leveling, TBC and Bernese was used for GNSS data processing and GRAVSOFT was used for gravity data processing. Airborne gravity data was integrated with surface gravity data to generate the precise geoid and hence orthometric height was calculated from the ellipsoid height obtained from the GNSS data processing for the top of the Sagarmatha. International Height Reference System (IHRS) was adopted as the common height datum for Nepal and China. The final height was determined as $8848.86 \mathrm{~m}$ (IHRS) jointly.

\section{TECHNICAL SUPPORT}

Technical support from different organization and personnel were also received for the successful conduction of this program. For the high altitude GNSS and gravity survey, it was supported by Simrik Air for helicopter service and for the GNSS survey at the peak, it was supported by Peak Promotion Pvt. Ltd. for Sagarmatha expedition. Trimble (Inc) supported with GNSS receivers and total station. The GNSS receiver was used to conduct GNSS survey at the top of the peak and the Total Station was used to measure the distance between two controls station during triangulation. National Geographic Society supported with meteorological stations and GPR. Further, Survey of India supported by conducting field work of precise survey to carry height to the datum station established at Maadar of Nepal from Indian bench mark which were connected from the sea level.

Besides these technical supports, other supports in capacity development were also received. Dr. Christopher Pearson from University of Otago, New Zealand visited 
Survey Department to train the staff from the department in GNSS data processing. On the request and budget from Survey Department, University of Bern, Switzerland conducted GNSS data processing in Bernese and Technical University, Denmark, conducted gravity data processing and geoid computation for the staff involved in data processing of this program.

\section{JOINT ANNOUNCEMENT}

Announcement of the height of Sagarmatha was conducted jointly between Nepal and China. The joint announcement was agreed between Nepal and China at president level, which was stated in the joint communiqué released during the visit of Chinese president to Nepal. After that, series of bilateral meetings were conducted between the two countries and formally formed Steering Committee and Technical Committee to finalize the common height and announce it jointly. From Nepal side, Steering Committee was led by Director General of Survey Department Mr. Prakash Joshi with the members Deputy Director General (DDG) Ms Karuna KC, DDG Mr Sushil Narsing Rajbhandari, DDG Mr Amir Prasad Neupane, DDG Mr. Susheel Dangol and Director Mr Damodar Dhakal. The Technical Committee from Nepal was led by Deputy Director General Mr Susheel Dangol with the members Mr Damodar Dhakal, Mr Sudeep Shrestha, Mr Suraj Bahadur KC, Mr Mahesh Thapa, Mr. Bigyan Banjara, Mr Shanker KC and Mr. Stalin Bhandari. Similarly, Steering committee from China was led by Director General of Department of Land Surveying and Mapping $\mathrm{Mr}$. Wu Wenzhong with the members DDG Dr Wang Qian, DDG Ms Chen Jun, Division Director Ms Jiang Xiaohong, Division Director Mr Yan Ronghua, Councilor Mr Sun LUshan, Dty. Division Diretor Mr $\mathrm{Li} \mathrm{Hu}$ and Director Prof. Dang Yamin. The technical team from China was led by Director of Chinese Academy of Surveying and Mapping Prof Dang Yamin with the members Mr Chunxi Guo, Prof. Chuanyin Zhang, Asst Prof. Tao Jiang, Mr. Chuanlu Cheng, Mr Bin Wang, Mr. Wenli Wang and Mr Quiang Yang.
Technical team finalized the height and submitted the final result to Steering committee on October 12, 2020 and Steering Committee agreed on the final height and submitted the final result to the respective government on October 18, 2020. The final height was approved for joint announcement from Council of Ministers, Government of Nepal on November 25, 2020 (2077/8/10).

On $8^{\text {th }}$ December 2020, the height was jointly announced by Foreign minister from both the countries Hon. Pradip Kumar Gyawali and Hon. Wang Yi and Minster for Land Management, Cooperatives and Poverty Alleviation Hon. Padma Kumari Aryal and Minister for Natural Resources Hon. Lu Hao. The height was announced by deliberating the message from Rt. Hon. President Bidya Devi Bhandari from Nepal and Xi Jinping from Peoples Republic of China.

\section{ACHIEVEMENT FROM THE PROGRAM}

Sagarmatha height measurement has given the new updated height of the peak after the devastating earthquake to the world. This is the direct product of the program. Besides this output, the program has brought different achievements. The most important and remarkable achievement is the development of human resources in the field of geodesy and mountain measurement. Since this was the first time Survey Department conducted the height measurement, department has developed capacity of the staff in mountain height measurement and geodetic data processing.

Another achievement is the establishment of infrastructure required for development activities. During the execution of this program, huge number of control points has been established. These control points are very necessary for survey works of infrastructure development activities. Hence, by using these points, the cost of the infrastructure development project will be reduced by the cost required for establishing this kind of control points. 


\section{CONCLUSION}

Orthometric height of the Sagarmatha was determined with the field measurement from latest technology. Nepal, for the first time conducted the height measurement of Sagarmatha and finalized the latest accurate height as $8848.86 \mathrm{~m}$ after the devastating earthquake occurred in Nepal. This result helps in giving solution to the query regarding the change in height of the peak after the earthquake. The joint announcement from Nepal and China further supported in fostering the friendly relation between the two countries showing the strong eternal relationship between both.

\section{REFERENCE}

Angus-Leppan, P.V. (1982). The Height of Mount Everest. Survey Review, Vol:26, Pg:367-385, DOI: 10.1179/sre. 1982.26.206.367

Chen J.Y. (1993). On the Redetermination for the Height of the World Highest Peak. In: Montag H., Reigber C. (eds) Geodesy and Physics of the Earth. International Association of Geodesy Symposia, vol 112. Springer, Berlin, Heidelberg. https://doi.org/10.1007/978-3-64278149-0_82.

Ward, M. (1995). The Height of Mount Everest. The Alpine Journal. 1995, Vol:100, Pg:30-33.

Gulatee, B. L. (1954). The Height of Mount Everest "A New Determination (1952-

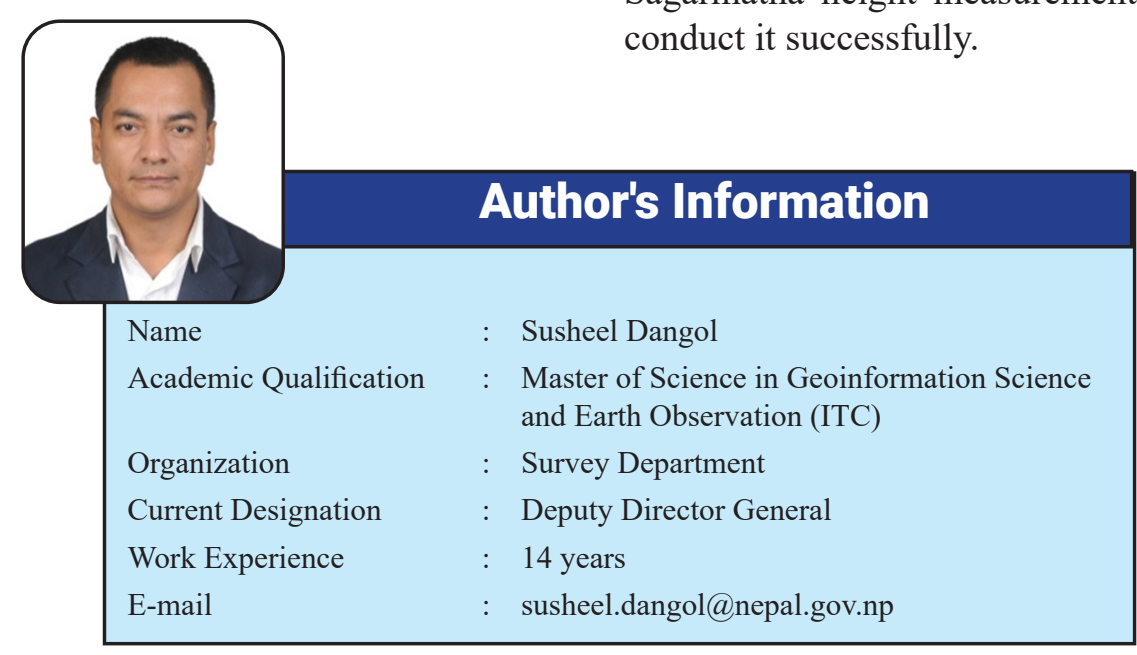

1954). Technical Paper No. 8, Survey of India.

Dansheng, G. (1979). The Determination of the Height of The Qomolangma Feng.

Beinat, A., Marchesini, C. \& Poretti, G. (1992). The New Measurement of Mount Everest. Scientific Report.

Poretti, G., Mandler, R. \& Lipizer, M. (2006). The Height of Mountains. Bollettino di Geofisica Teorica ed Applicata, Vol 47, n 4, Pg. 557-575.

Yamin, D., Chuanlu, C., Junyong, C. \& Peng Z. (2007). Geodetic Height Determination in 2005 Qomolangma Survey. Geospatial Information Science, Vol 10, Issue 2, DOI-10.1007/s11806-0070042-z

Chen, J., Zhang, Y., Yuan, J.,Guo, C. \& Zhang, P. (2010). Height Determination of Qomolangma Feng (Mt. Everest) in 2005. Survey Review. Vol 42, Issue 316.

Chen, J, Yuan, J., Guo, C., Zhang, Y. \& Zhang, P. (2006). Progress in Technology for the 2005 Height Determination of Qomolongma Feng (Mt. Everest). Science in China Series D 49, 531-538 (2006). https://doi.org/10.1007/s11430006-0531-1, Springer Publication.

\section{ACKNOWLEDGEMENT}

Authors would like to acknowledge all the technical persons who were involved in the field and all other personnels and organizations who directly or indirectly supported this Sagarmatha height measurement program to conduct it successfully. 